\title{
Active Transport of the Survival Motor Neuron Protein and the Role of Exon-7 in Cytoplasmic Localization
}

\author{
Honglai L. Zhang, ${ }^{1}$ Feng Pan, ${ }^{2}$ Daewha Hong, ${ }^{1,2}$ Shailesh M. Shenoy, ${ }^{2}$ Robert H. Singer, ${ }^{2}$ and Gary J. Bassell ${ }^{1}$ \\ Departments of ${ }^{1}$ Neuroscience, Rose F. Kennedy Center for Mental Retardation, and ${ }^{2}$ Anatomy and Structural Biology, Albert Einstein College of Medicine, \\ Bronx, New York 10461
}

\begin{abstract}
Spinal muscular atrophy (SMA) is a neurodegenerative disease caused by deletion and/or mutation of the survival motor neuron protein Gene (SMN1) that results in the expression of a truncated protein lacking the $\mathrm{C}$ terminal exon-7. Whereas SMN has been shown to be an important component of diverse ribonucleoprotein (RNP) complexes, its function in neurons is unknown. We hypothesize that the active transport of SMN may be important for neurite outgrowth and that disruption of exon-7 could impair its normal intracellular trafficking. SMN was localized in granules that were associated with cytoskeletal filament systems and distributed throughout neurites and growth cones. Live cell imaging of enhanced green fluorescent protein (EGFP)-SMN granules revealed rapid, bidirectional and cytoskeletaldependent movements. Exon-7 was necessary for localization of SMN into the cytoplasm but was not sufficient for granule formation and transport. A cytoplasmic targeting signal within exon-7 was identified that could completely redistribute the nuclear protein D-box binding factor 1 into the cytoplasm. Neurons transfected with SMN lacking exon-7 had significantly shorter neurites, a defect that could be rescued by redirecting the exon-7 deletion mutant into neurites by a targeting sequence from growth-associated protein-43. These findings provide the first demonstration of cytoskeletal-based active transport of SMN in neuronal processes and the function of exon-7 in cytoplasmic localization. Such observations provide motivation to investigate possible transport defects or inefficiency of SMN associated RNPs in motor neuron axons in SMA.
\end{abstract}

Key words: survival motor neuron protein; spinal muscular atrophy; mRNA transport; mRNA localization; active transport; growth cone; neurite outgrowth

\section{Introduction}

Spinal muscular atrophy (SMA) is one of the most common inherited diseases that results in infant death, characterized by a neurodegenerative process affecting primarily $\alpha$-motor neurons of the lower spinal cord (Frugier et al., 2002). SMA is caused by deletions or mutations of the survival motor neuron protein gene (SMN1) (Lefebvre et al., 1995), which encodes a protein known to be essential for the assembly of diverse ribonucleoprotein (RNP) complexes (Terns and Terns, 2001; Paushkin et al., 2002). SMN1 is an essential gene in divergent organisms, and the protein is ubiquitously expressed in all tissues (Paushkin et al., 2002), with high levels in the nervous system and especially spinal cord (Battaglia et al., 1997). In humans, the SMN gene is duplicated with a telomeric copy, SMN1, that expresses a full-length protein and a centromeric copy, SMN2, that encodes a truncated isoform with deletion of the $\mathrm{C}$ terminal exon-7. SMA is caused by loss of the full-length protein that results primarily from deletions or mutations in exon-7, suggesting its critical importance for SMN function (Wirth, 2000).

\footnotetext{
Received April 2, 2003; revised May 16, 2003; accepted May 29, 2003

This work was supported by a Muscular Dystrophy Foundation grant to Honglai Zhang and National Institutes of Health Grant GM55599 to G.B. We thank Phillip Young and Glen Morris for providing SMN monoclonal antibodies, Than Le and Arthur Burghes for SMN1 CDNA, and Marten Smidt for DBF1 CDNA. We thank Michael Plociniak and Andrew Levine for technical assistance and Laura Antar for helpful comments.

Correspondence should be addressed to Dr. Gary Bassell, Department of Neuroscience, Albert Einstein College of Medicine, 1410 Pelham Parkway, Bronx, NY 10461. E-mail: bassell@aecom.yu.edu.

Copyright $\odot 2003$ Society for Neuroscience $\quad$ 0270-6474/03/236627-11\$15.00/0
}

SMN is localized to both the nucleus and cytoplasm, and considerable attention has focused on concentration of SMN in nuclear dot-like structures termed gems (Liu and Dreyfuss, 1996) and coiled (Cajal) bodies (Carvalho et al., 1999; Young et al., 2000). There have been extensive studies, in various cell lines of non-neuronal origin, on the targeting of SMN to these nuclear substructures and its function in spliceosome assembly and premRNA splicing (Paushkin et al., 2002). Despite this vast knowledge of SMN biochemistry, it remains unclear how a ubiquitous function for SMN in spliceosome assembly can lead to a neuronal phenotype characterized by a neurodegenerative process. A major question is whether SMN has distinct functions in neurons, which when disrupted, could impair neuronal growth and differentiation. We feel that insight into this issue must come from study of SMN in a neuron.

An alternative view of SMN function is that it is an essential component of RNP complexes that are actively transported in neuronal processes. Immunocytochemical studies have localized SMN in dendrites (Bechade et al., 1999; Pagliardini et al., 2000) and axons (Pagliardini et al., 2000) of spinal cord motor neurons in vivo. Labeling of SMN at the electron microscope level suggests its association with cytoskeletal filaments (Bechade et al., 1999; Pagliardini et al., 2000) and polyribosomes (Bechade et al., 1999). These immunocytochemical studies suggest the possibility that SMN may be actively transported into neuronal processes.

Here we show that SMN was localized in granules that were 
localized in neurites and growth cones of cultured neurons. SMN granules exhibited rapid, bidirectional movements that were dependent on both microtubules and microfilaments. We further showed that the $\mathrm{C}$ terminal exon-7 contains a sequence that is essential for localization of SMN in the cytoplasm. Overexpression of an exon-7 deletion mutant was characterized by abnormal accumulation of SMN in the nucleus and reduced neurite outgrowth. These findings demonstrate the active transport of SMN and the role of exon-7 in cytoplasmic localization, which offers new insight into the biological basis of the neurodegeneration observed in SMA.

\section{Materials and Methods}

Cell culture. Two methods were used for primary neuronal culture: embryonic chick forebrain or rat spinal cord. Chick forebrains [embryonic day 8 (E8)] were dissected, trypsinized $\left(0.15 \%\right.$ in HBSS) at $37^{\circ} \mathrm{C}$ for 7 min, and plated on poly-L-lysine and laminin A coated coverslips. Dissociated neurons were cultured for $4 \mathrm{~d}$ in $\mathrm{N}_{3}$-conditioned medium with $2 \%$ FBS (Zhang et al., 1999). Rat spinal cords (E15) were dissected, and ventral regions were cut into small pieces and trypsinized ( $0.1 \%$ in HBSS) at $37^{\circ} \mathrm{C}$ for $10 \mathrm{~min}$. The tissues were gently dissociated by triturating in minimal essential medium (MEM) with $10 \%$ FBS (Sigma, St. Louis, $\mathrm{MO}$ ). Large motor neurons were harvested by density gradient centrifugation through 6.8\% metrizamide cushion in Leibovitz's L-15 medium (Invitrogen, Gaithersburg, MD) at $500 \times g$ for $10 \mathrm{~min}$. After washing twice in MEM, the cells were plated at low density $\left(5000 \mathrm{cells} / \mathrm{cm}^{2}\right)$ on poly-D-lysine $(25 \mu \mathrm{g} / \mathrm{ml}, 16 \mathrm{hr})$ and laminin A $(0.02 \mathrm{mg} / \mathrm{ml}, 12 \mathrm{~min})$ coated coverslips in MEM with 10\% FBS for $2 \mathrm{hr}$. Cells were inverted onto a monolayer of rat astrocytes in $\mathrm{N}_{3}$-conditioned medium with $0.5 \%$ FBS, $10 \mathrm{ng} / \mathrm{ml} \mathrm{NGF}, 25 \mathrm{ng} / \mathrm{ml} \mathrm{NT}-3$, and $25 \mathrm{ng} / \mathrm{ml} \mathrm{BDNF}$, and cultured for $3 \mathrm{~d}$ at $37^{\circ} \mathrm{C}$ in $5 \% \mathrm{CO}_{2}$. $\mathrm{N}_{3}$-conditioned medium contained MEM supplemented with transferrin $(0.2 \%)$, ovalbumin $(0.1 \%)$, insulin (10 $\mu \mathrm{g} / \mathrm{ml})$, putrescine $(32 \mu \mathrm{g} / \mathrm{ml})$, sodium selenite $(26 \mathrm{ng} / \mathrm{ml})$, progesterone (12.5 ng/ml), hydrocortisone $(9.1 \mathrm{ng} / \mathrm{ml}), \mathrm{T} 3$ (3, 3', 5'-tri-iodo-Lthyronine, sodium salt, $20 \mathrm{ng} / \mathrm{ml})$, and BSA $(10 \mu \mathrm{g} / \mathrm{ml})$.

For fluorescence in situ hybridization and immunofluorescence analysis, cells were fixed in paraformaldehyde ( $4 \%$ in $1 \times$ PBS) for $20 \mathrm{~min}$ at room temperature and washed in $1 \times \mathrm{PBS}$ with $5 \mathrm{mM} \mathrm{MgCl}_{2}$ three times.

Enhanced green fluorescent protein reporter constructs and neuron transfection. Full-length cDNA of the human SMN1 was subcloned into an enhanced green fluorescent protein (EGFP)-C1 vector (BD Biosciences Clontech, Palo Alto, CA) and was designated EGFP-SMN. SMN cDNA with deletions of exon-7, exon-5, or both exon- 5 and -7 were generated by PCR via specific primers and then inserted into the EGFP-C1 vectors, respectively, termed EGFP-SMN $\Delta$ Ex7, EGFP-SMN $\Delta$ Ex5, and EGFP-SMN $\Delta$ Ex $5 \& 7$. A cytoplasmic targeting sequence (mem) of growth-associated protein-43 (GAP-43) was obtained from the pECFP-mem construct (BD Biosciences Clontech) and was subcloned into the $\mathrm{N}$ terminus of the EGFP reporter in EGFP-SMN $\Delta \mathrm{Ex} 7$ and EGFP$\mathrm{SMN} \Delta \mathrm{Ex} 5 \& 7$ and was designated mem/EGFPSMN $\Delta$ Ex7 and mem/EGFP-SMN $\Delta$ Ex $5 \& 7$.

D-box binding factor 1 (DBF1) was used as a nuclear reporter to investigate the role of SMN exon-7 in localization. DBF1 is a singlestranded DNA binding protein that is normally localized to the nucleus (Smidt et al., 1995). DBF1 cDNA (906 bp) was subcloned into the EGFP-C1 vector and designated EGFP-DBF1. The SMN exon-7 cDNA was subcloned into the $\mathrm{C}$ terminus of DBF1 in EGFP-DBF1 and was designated as EGFP-DBF1/Ex7. The GAP-43 membrane targeting sequence was also fused to EGFP-DBF1, designated as mem/EGFP-DBF1 (Table 1).

To identify a targeting motif (tif) within SMN exon-7, three overlapping fragments within the exon-7 were designed: termed "P"
Table 1. Schematic of the EGFP-reporter constructs for transfection

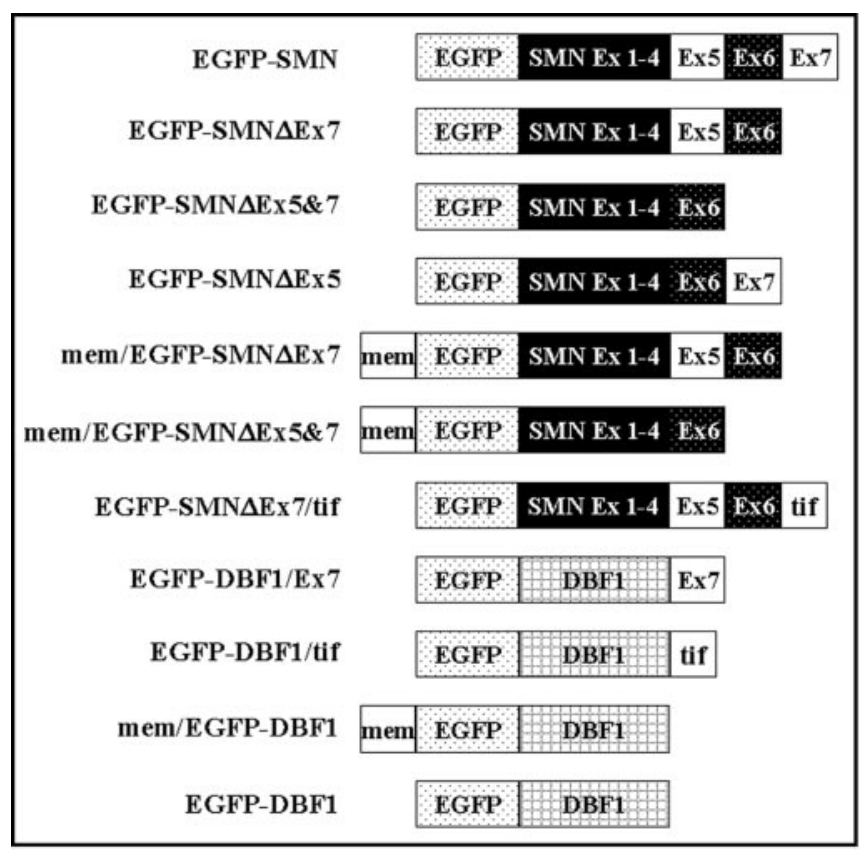

for proximal subregion (first 8 amino acids), " $M$ " for middle subregion (middle 9 amino acids), and " $D$ " for distal subregion (last 8 amino acids). These cDNAs were synthesized and inserted into the $\mathrm{C}$ terminus of EGFP-DBF1, and designated as EGFP-DBF1/P, EGFP-DBF1/M, and EGFP-DBF1/D (see Fig. 7). A five amino acid sequence, Gln-Asn-GlnLys-Glu (QNQKE) from SMN exon-7, was also inserted into the C terminus of EGFP-SMN $\Delta$ Ex7 and EGFP-DBF1, designated as EGFP$\mathrm{SMN} \Delta \mathrm{Ex} 7 / \mathrm{tif}$ and EGFP-DBF1/tif, respectively (targeting motif::tif). All of the constructs were purified (Qiagen, Hilden, Germany) and sequenced to ensure that no frame shift had occurred.

Cultured neurons were transfected with the above constructs using DOTAP liposomal reagent (Roche) and cultured for $4 \mathrm{~d}$, as described previously (Zhang et al., 2001). The cells were fixed in $4 \%$ paraformaldehyde for $20 \mathrm{~min}$ at room temperature. Images were captured using a cooled CCD camera with a fluorescence microscope. For live cell imaging, transfected neurons were grown on Bioptechs coverslips (40 mm) for $4 \mathrm{~d}$ after transfection (described below).

Cytoskeletal disruption experiments. One hour before imaging, transfected neurons were treated with either colchicine (10 $\mu \mathrm{g} / \mathrm{ml}$; Sigma) or cytochalasin-D ( $5 \mu \mathrm{g} / \mathrm{ml}$; Sigma). The cells were imaged live in the pres-
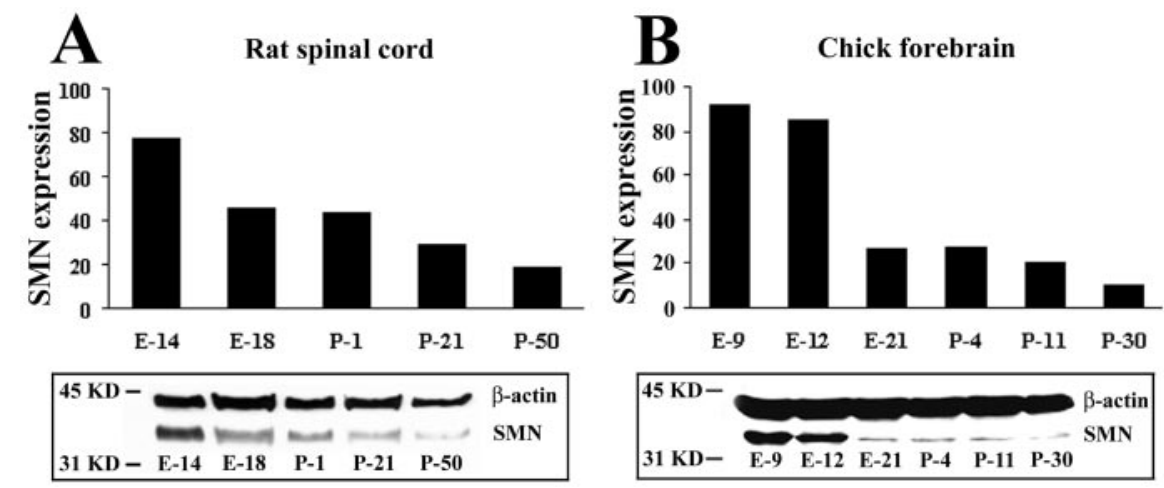

Figure 1. Western blot analysis of SMN expression from rat spinal cord and chick forebrain at different embryonic stages. $A$, In rat spinal cord, SMN expression was prominent at embryonic stages and declined developmentally. $B$, In chick forebrain, SMN was also highly expressed at embryonic stages and declined after birth. $A, B$, Density ratio of $S M N$ to $\beta$-actin is shown in the top panel. SMN was detected with a monoclonal antibody and showed a single band at $38 \mathrm{kDa}$. $\beta$-actin was detected with a monoclonal antibody and showed a single band at $42 \mathrm{kDa}$, blotted on the same membrane as an internal control. 

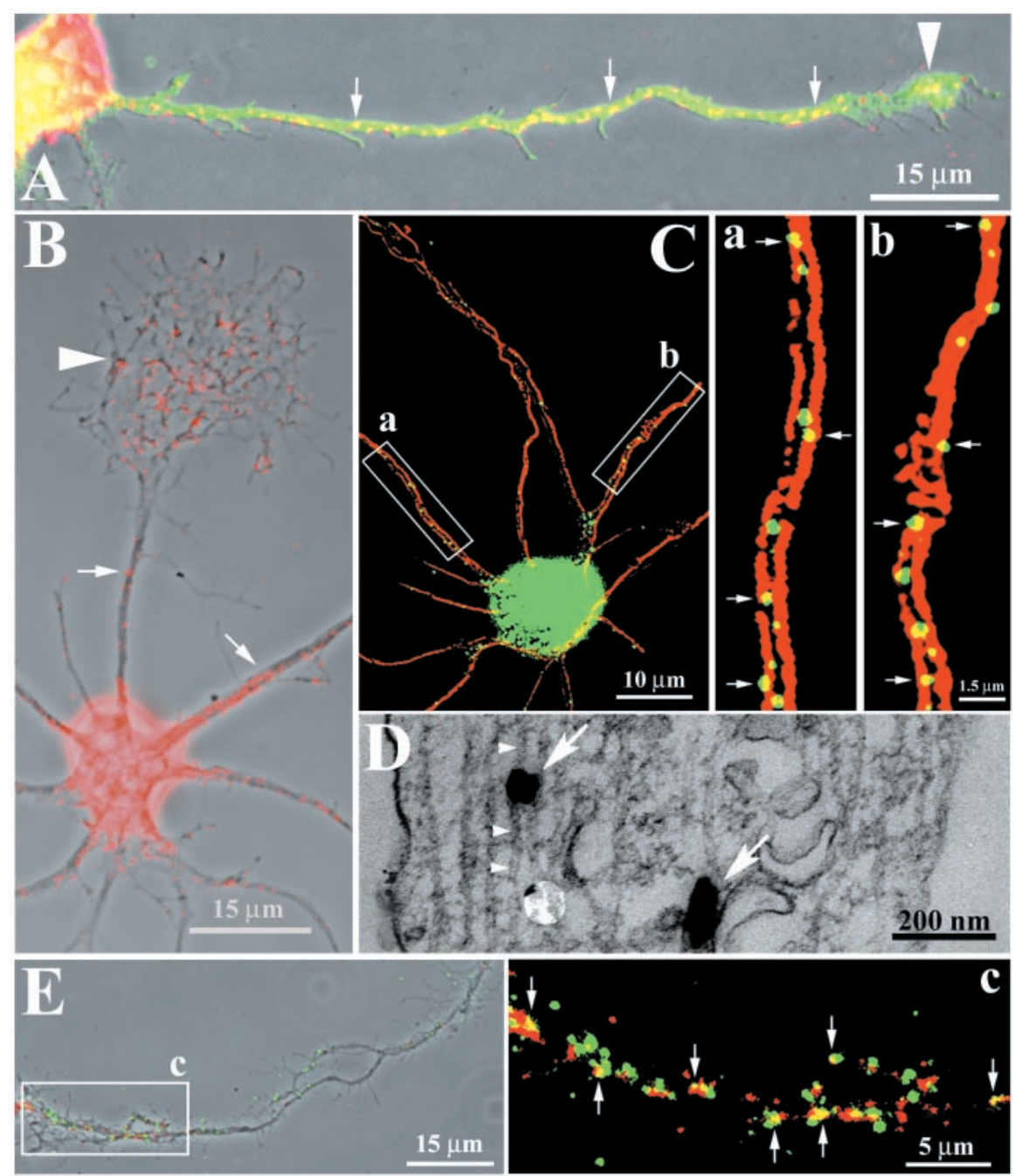

Figure2. Localization and microtubule association of SMN granules in neuronal processes and growth cones. $A$, Rat spinal cord neurons were cultured for $3 \mathrm{~d}$ and fixed for double label immunofluorescence staining with a monoclonal antibody to SMN (red) and a rabbit polyclonal antibody to tau (green), as an axonal marker. SMN formed granules that localized to the axonal process (arrows) and its growth cone (arrowhead). B, Cultured chick forebrain neurons stained with the monoclonal antibody to SMN showed SMN granules (red) within minor neurites (arrows) and growth cones (arrowhead). C, Transfection of EGFP-SMN in chick forebrain neurons similarly revealed granules within processes. Microtubules were detected with a monoclonal antibody and (y3-labeled anti-mouse antibody (red). Z-series stacks were acquired with a cooled CCD camera, and images were deconvolved (Hazebuster; Vaytek). Higher magnification of two regions $(a, b)$ suggest association of EGFP-SMN granules (yellow, arrows) and microtubules. D, Immunogold detection of SMN (arrows) at the EM levels shows proximity to microtubules (arrowheads) within neuronal processes. E, Rat spinal cord neuron showed colocalization of SMN (green) with ribosomal RNA (red). Ribosomal RNA was detected by biotin-labeled oligonucleotide probes and Cy3-conjugated streptavidin. SMN was stained with a monoclonal antibody and (y5-conjugated anti-mouse antibody. Higher magnification region (c) indicates SMN colocalization with ribosomal RNA (yellow, arrows).

ence of the drugs. Our previous work has shown that microtubules are depolymerized in these neurons after $1 \mathrm{hr}$ of colchicine treatment. One hour treatment of cytochalasin-D also significantly disrupts actin filaments (Zhang et al., 1999).

Similarly, transfected chicken embryonic fibroblasts were subjected to Triton X-100 extraction with or without $30 \mathrm{~min}$ treatment with cytochalasin-D or colchicine. Briefly, cytochalasin-D $(5 \mu \mathrm{g} / \mathrm{ml})$ or colchicine $(10 \mu \mathrm{g} / \mathrm{ml})$ was added to the media for $30 \mathrm{~min}$. Cell were rinsed twice with prewarmed PEM buffer ( 80 mM PIPES, 4 mM EGTA, 1 mM $\mathrm{MgCl}_{2}, 10 \%$ glycerol), then extracted for $30 \mathrm{sec}$ in PEM buffer with $0.5 \%$ Triton X-100 and protease inhibitor cocktail (Roche, Hertfordshire, UK). Cells were fixed in $4 \%$ paraformaldehyde. Microfilaments were visualized by phalloidin labeled with Texas Red.

In situ hybridization and immunofluorescence analysis. Four aminomodified oligonucleotides (50 bases each), complementary to ribosomal RNA (18 S) of rat, were synthesized on a DNA synthesizer and chemically labeled using biotin succinamide ester (Roche Molecular Biochemicals). In situ hybridization for ribosomal RNA was completed as previously described (Zhang et al., 1999, 2001). The biotin-labeled oligonucleotide probe was detected by immunofluorescence using Cy3conjugated streptavidin (Jackson ImmunoResearch, West Grove, PA). Coverslips were mounted with gelvatol containing $N$-propyl gallate $(6 \mathrm{mg} / \mathrm{ml})$ as an anti-bleaching agent.

For detection of endogenous proteins, we used monoclonal antibodies to SMN (BD Biosciences) or tubulin (Sigma). A rabbit polyclonal antibody was used to detect tau (Sigma). All secondary antibodies were affinity-purified donkey antibodies to mouse or rabbit IgG conjugated to a fluorochrome (Jackson ImmunoResearch). Antibody incubations were for 1 $\mathrm{hr}$ at room temperature in Tris-buffered saline (TBS) with BSA (1\%) and Triton X-100 (0.1\%). Coverslips were mounted as described above.

Fluorescence microscopy and digital imaging. Neurons were visualized using a Nikon Eclipse inverted microscope equipped with a $60 \times$ Plan-Neofluar objective, phase optics, $100 \mathrm{~W}$ mercury arc lamp, and HiQ bandpass filters (Chroma Technology, Brattleboro, VT). Images were captured with a cooled CCD camera (Quantix; Photometrics) using a $35 \mathrm{~mm}$ shutter and processed using IP Lab Spectrum (Scanalytics). Fluorescence images of ribosomal RNA (in situ hybridization) and proteins (immunofluorescence) were then acquired with specific filters, including Cy2, Cy3, or Cy5. Exposure time was kept constant and below gray scale saturation. Quantitative analysis of neurite length in each transfection was completed on phase optics from duplicated coverslips. The longest neurites from more than 60 transfected neurons were measured using computer IP Lab software.

For live cell imaging as described previously (Zhang et al., 2001), neurons were transfected with an EGFP-SMN construct and cultured on Bioptechs coverslips $(40 \mathrm{~mm})$ for $4 \mathrm{~d}$ in $\mathrm{N}_{3}$ conditioned medium. Coverslips were transferred to a sealed environmental chamber (Bioptechs Focht Chamber) in $\mathrm{N}_{3}$-conditioned medium that was from the same cell culture dish. Imaging of live neurons was performed using a TILL Photonics Imaging System with a Polychrome II monochromator and high-resolution Imago CCD camera. Cells were imaged at an exposure rate of 0.5 $\mathrm{sec}$ for each frame, with a total of 200 frames. For each granule, the velocity (in micrometers per second), distance (in micrometers), and direction (anterograde or retrograde) were analyzed using IP Lab software.

After colchicine or cytochalasin-D treatment, 10 transfected neurons were imaged for each condition. A region of interest (ROI) in neuronal process was chosen at least $10 \mu \mathrm{m}$ away from the cell body, between 10 and $50 \mu \mathrm{m}$ within the processes. One ROI was selected in each imaged neuron, and all granules within the ROI were scored as "directed" if the net displacement was $>2 \mu \mathrm{m}$ in one direction, "nondirected" for oscillatory or bidirectional displacements ( $<2 \mu \mathrm{m}$ displacement), and "stationary" if no motility was observed. More than 300 small granules and 100 large granules in each treatment condition were analyzed using a computer SAS program in determination of "frequency" of each granule within the above-defined categories.

To analyze the GFP-SMN signal retained on the cytoskeleton after Triton X-100 extraction, transfected chicken embryonic fibroblasts were 
viewed on an Olympus BX61 microscope equipped with an Olympus PlanApo 60×, 1.4 NA oil objective. Images were captured by a Roper CoolSnap HQ cooled CCD camera operated by IP lab software. At least 80 cells from two independent experiments were selected individually, and the ROI was analyzed. Average arbitrary fluorescence intensity for each cell was calculated by IP lab software.

Electron microscopy. Pre-embedment immunogold labeling was performed on $4 \mathrm{~d}$ cultured in vitro chick forebrain neurons using monoclonal anti-SMN antibody and transmission electron microscopy (TEM). Cells were washed briefly in MEM and then fixed for 15 min (4\% paraformaldehyde and $0.1 \%$ glutaraldehyde in $0.1 \mathrm{M}$ sodium cacodylate). Cells were incubated with primary antibody diluted 1:750 in blocking buffer (TBS, 2\% BSA) for $15 \mathrm{hr}$ at $4^{\circ} \mathrm{C}$ and washed several times in the buffer. Goldconjugated $(1 \mathrm{~nm})$ secondary antibodies (Amersham Biosciences, Arlington Heights, IL) were applied for $3.5 \mathrm{hr}$ incubation and followed by washing several times. Cells were postfixed ( $2.5 \%$ glutaraldehyde) and stained with $1 \%$ osmium tetroxide and $1.5 \%$ potassium ferricyanide in buffer for $20 \mathrm{~min}$. Ultrasmall gold particles were enhanced (Goldenhance-EM; Nanoprobes) for $10 \mathrm{sec}$. Cells were stained with $1 \%$ aqueous uranyl acetate ( $\mathrm{pH} 4.2$ ) for $20 \mathrm{~min}$, then dehydrated completely. Samples were embedded and sectioned by standard procedures. Sections were stained with $4 \%$ uranyl acetate and $0.2 \%$ lead citrate $(3 \mathrm{~min}$ at room temperature). A Jeol 1200 EX TEM was operated at 60 $\mathrm{kV}$ to image immunogold labeling.

Western blot. Protein extracts $(10 \mu \mathrm{l})$ from rat spinal cords and chick forebrains at different embryonic stages were resolved by $12 \%$ SDSPAGE, and fractionated proteins were transferred to Hybond ECL nitrocellulose membrane (Amersham) at $4^{\circ} \mathrm{C}$ overnight. SMN was detected with a monoclonal antibody (1:500 diluted in TBS buffer). The membrane was washed and incubated with peroxidaseconjugated donkey anti-mouse IgG (Jackson ImmunoResearch). The signal was developed using ECL detection reagents (Amersham).

\section{Results}

Active transport of SMN granules to developing neurites and growth cones

Our previous studies on the localization and active transport of mRNA and mRNA

binding proteins have used cultured forebrain neurons from chick embryos as a model system (Zhang et al., 1999, 2001). We have noted several advantages of these neurons that include the ability to transfect them at moderate efficiency and with minimal toxicity. All of the transfection experiments with human SMN constructs, discussed below, were done in this culture system. Analysis of SMN expression and subcellular localization was done, in addition, with cultured spinal cord neurons from rat embryos. Western blot analysis using a monoclonal antibody to SMN recognized a single band of approximate molecular weight $38 \mathrm{kDa}$, from both of the above tissue sources, similar to previous results (Young et al., 2000). Comparison of chick forebrain and rat spinal cord tissues indicated that SMN expression was robust during embryonic stages and declined developmentally (Fig. 1). Decreased expression of SMN was observed after E14 in rat spinal cord (Fig. 1A) and after E9 in chick forebrain (Fig. 1B). SMN was only weakly expressed in adult brain and spinal cord. These quantitative results indicate developmental regulation of SMN in different nervous system tissues and further extend previous findings that SMN levelsdecline postnatally (Burlet et al., 1998; La Bella et al., 1998; Germain-Desprez et al., 2001).

To investigate the subcellular localization of SMN, immunofluorescence analysis was performed using the above monoclonal antibody on cultured rat spinal cord and chick forebrain neurons. Spinal cord (E15) and forebrain (E8) neurons were cultured at stages in which SMN is expressed at high levels. SMN was abundant in the cell body and also distributed throughout processes in 

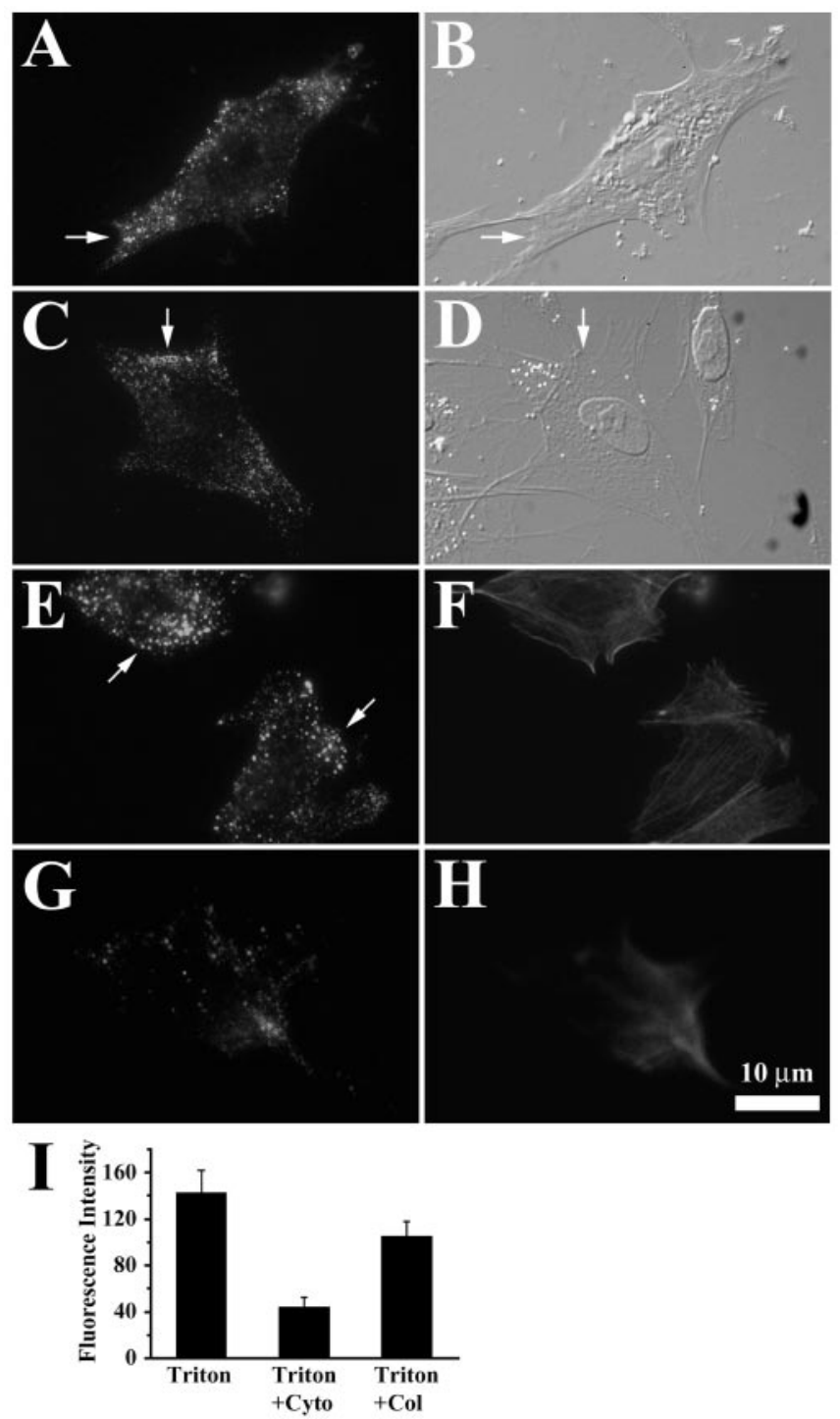

Figure 4. Association of EGFP-SMN with the actin cytoskeleton in fibroblasts. A, EGFP-SMN was distributed predominantly in the cytoplasm and signal often accumulated at the leading edge of cultured fibroblast (arrow). One or two dots were also observed in the nucleus. $B$, Corresponding DIC image. C, EGFP-SMN granules were retained after Triton X-100 extraction in buffer (arrow). D, DIC image. E, Retention of EGFP-SMN on the cytoskeleton after colchicine treatment and Triton X-100 extraction (arrows). F, This procedure did not disrupt actin filaments, although microtubules were depolymerized (data not shown). G, In contrast, cytochalasin-D and Triton X-100 extraction released EGFP-SMN, and little signal was apparent. $H$, Note the disruption of most actin filaments after cytochalasin-D treatment. I, Quantitative analysis of the mean cytoplasmic fluorescence intensity in Triton X-100 extracted cells demonstrated a $70 \%$ reduction after cytochalasin-D treatment and a $26 \%$ reduction after colchicine treatment.

a highly punctuate or granular pattern in both rat spinal cord neurons (Fig. 2A) and chick forebrain neurons (Fig. 2B). SMN granules were observed in both the minor neurites and the longer axon-like process; the latter was identified with anti-tau reactivity (Fig. 2A). SMN granules within axons were also detected in the growth cone (Fig. $2 A$, arrowhead). A similar distribution of SMN was observed in chick forebrain neurons (Fig. $2 B$ ). These neurons have large, elaborate growth cones that contained many SMN granules (arrowhead).

We performed experiments to determine whether SMN granules were actively transported into processes and associated with cytoskeletal filaments. Fluorescence imaging of neurons trans- fected with human EGFP-SMN was first done in fixed cells to show that the distribution of EGFP-SMN was similar to that obtained by immunofluorescence. EGFP-SMN was observed in granules within processes (Fig. 2C). Immunofluorescence with anti-tubulin antibody, done on neurons transfected with EGFPSMN, suggested an association or possible coalignment of SMN granules with microtubules, in deconvolved optical sections (Fig. $2 C$, insets $a, b)$. A similar association was also depicted at the EM level using silver-enhanced immunogold with the anti-SMN antibody (Fig. 2D). Silver-enhanced gold particles were often observed on microtubules. Double-label detection of SMN and biotin-conjugated oligonucleotides to ribosomal RNA (18 S) showed frequent colocalization within neuronal processes and the growth cone (Fig. 2E). These experiments suggest an association between SMN granules and microtubules that could provide the basis for active transport of SMN-containing RNP complexes.

Live cell imaging of cultured forebrain neurons, transfected with EGFP-SMN, revealed granules that exhibited dynamic bidirectional and unidirectional movements in processes (Fig. $3 A$ ). The long distance trajectories of several granules in this field are illustrated (long white arrows). Most of the granules showing these types of directed movements tended to be small in size. We also observed larger granules that exhibited predominantly nondirected or oscillatory behavior (short black arrows). A quantitative frame-by-frame analysis was done on both types of granules. Small granules often revealed consistent persistent movements that resulted in long trajectories $(>10 \mu \mathrm{m})$ in either anterograde (Fig. 3B) or retrograde (Fig. 3C) directions. Both anterograde and retrograde moving granules were often observed to change directions (Fig. 3D). Granules were also observed to continue a trajectory beyond a branch point (Fig. 3A) (see also video 1, available at www.jneurosci.org). Here, a granule took a rapid retrograde trajectory in the primary neurite toward a branch point and then moved anterogradely in the secondary neurite. The average velocity of small granule movements was $1 \mu \mathrm{m} / \mathrm{sec}$, however, instantaneous velocities of $>2.5 \mu \mathrm{m} / \mathrm{sec}$ were frequently observed for short durations. In contrast to the persistent movements of small granules, the large granules exhibited oscillatory movements with frequent direction changes resulting in no net displacement (Fig. 3E). Occasionally, these large granules did exhibit bidirectional movements that resulted in small net displacements in one direction $(<2 \mu \mathrm{m})$. Rates of oscillatory granules were slower than those of persistent granules, with instantaneous velocities typically $<0.5 \mu \mathrm{m} / \mathrm{sec}$.

We investigated the effects of cytoskeletal perturbing drugs on granule movements in live neurons. Transfected neurons were incubated for $1 \mathrm{hr}$ in the presence of either colchicine $(10 \mu \mathrm{g} / \mathrm{ml})$, to depolymerize microtubules, or cytochalasin-D $(5 \mu \mathrm{g} / \mathrm{ml})$, to disrupt actin filaments. Granules were scored in three categories: directed granules were defined by movements with $>2 \mu \mathrm{m}$ displacement in one direction. Nondirected granules were defined by rapid movements with frequent direction changes and a net displacement of $<2 \mu \mathrm{m}$. Stationary granules were defined by an absence of dynamic movements between frames. After colchicine treatment, we observed a $47 \%$ decrease in the percentage of directed granules, with a corresponding increase in stationary granules (Fig. 3F). There was also a significant decrease $(39 \%)$ in directed movements after cytochalasin-D treatment (Fig. $3 F$ ). These results indicated a role for both microtubules and microfilaments in directed granule movements. However, we noted that the very long trajectories, i.e., $>10 \mu \mathrm{m}$, were only observed in cytochalasin-D treated cells and not colchicine treated cells, 
suggesting a role of microtubules in longdistance directed movements. Large granules exhibited predominantly oscillatory movements that were dependent on actin filaments (Fig. 3G). Large granules also exhibited directed movements over short distances, which were dependent on microtubules and actin filaments. These studies show a role of microtubules in directed movements over long distances and a role for actin filaments in short-distance directed movements and oscillatory movements.

\section{Predominant association of SMN with microfilaments in fibroblasts}

We investigated whether SMN was physically associated with the cytoskeleton. The approach involves extraction of cells with the non-ionic detergent Triton X-100 $(0.5 \%)$ in a cytoskeletal preservation buffer before fixation (see Materials and Methods). Under these conditions, soluble proteins and most membrane organelles are extracted, leaving behind cytoskeletal filament systems and bound mRNAs and polyribosomes (Bassell and Singer, 2001). Unfortunately, this type of detergent extraction is too harsh to preserve neuronal processes, yet cultured fibroblasts can tolerate such an extraction because they are very flat and firmly adhered to the substrate. Several mRNAs and binding proteins have been shown to be retained on the fibroblast cytoskeleton using this approach (Bassell and Singer, 2001).

Chicken embryonic fibroblasts were transfected with an EGFP-SMN construct and visualized by fluorescence microscopy. GFP-SMN was present in granules that distributed throughout the cytoplasm with moderate enrichment in the fibroblast leading edge in unextracted cells (Fig. $4 A, B$, arrow), and this distribution was maintained after Triton X-100 extraction (Fig. 4C,D, arrow). Fibroblasts were then treated with either cytochalasin-D or colchicine and then subjected to Triton X-100 extraction and fixation. These experiments showed that the majority of SMN (70\%) was released from the cytoskeleton after perturbation of actin filaments (Fig. 4G,I), whereas depolymerization of microtubules released $26 \%$ of SMN (Fig. 4E,I), suggesting an association of SMN with both filament systems, but predominantly microfilaments in these cells.

\section{Role of SMN exon-7 in cytoplasmic localization}

The majority of mutations and deletions in SMA are in the $\mathrm{C}$ terminal exon-7. A possible role of exon-7 in localization of SMN in neuronal processes has not been elucidated. We hypothesize that exon-7 is necessary for the localization of SMN in neuronal processes. Several truncations of human SMN1 cDNA were constructed and fused to EGFP. These include: an exon-7 deletion (EGFP-SMN $\Delta$ Ex7), exon-5 deletion (EGFP-SMN $\Delta$ Ex5), and a deletion of both exon-5 and exon-7 (EGFP-SMN $\Delta$ Ex $5 \& 7$ ). All constructs were sequenced to ensure that no frame shifts had occurred. Chick forebrain neurons were transfected with the above constructs. In comparison with full-length EGFP-SMN, which exhibited granules in the perinuclear cytoplasm and pro- cesses (Fig. 5A,B), we observed that the exon-7 deletion mutant (EGFP-SMN $\Delta \mathrm{Ex} 7)$ showed an exclusive nuclear localization (Fig. 5E,F). Moreover, its levels in the nucleus were considerably higher than those observed for wild-type SMN. Deletion of exon-5 did not disrupt SMN localization into the cytoplasm and processes (Fig. 5C,D). Deletion of exon-5 and exon-7 also showed an exclusive nuclear localization that was similar to the exon-7 deletion mutant (Fig. 5G,H). Of interest, we noted that neurons transfected with constructs lacking exon-7 had shorter neurites (this result is addressed further in experiments discussed below).

To study the nuclear localization of SMN constructs with higher resolution, we analyzed optical sections along a Z-series and performed deconvolution that was useful to study spatial colocalization between SMN and coilin, a marker for coiled bodies. Neurons transfected with full-length EGFP-SMN demonstrated one or two foci of SMN that colocalized with coilin (Fig. $6 A-C$, arrowhead). In the cytoplasm, EGFP-SMN was abundant in the perinuclear region and extended into processes in the form of granules (arrows). Although the exon-7 deletion mutant also showed colocalization with coilin foci in the nucleus (Fig. $6 E-G$, arrow), there were clearly many other nuclear foci that were positive for SMN but did not contain coilin (Fig. 6E-G, arrows). Another striking pattern of the exon-7 deletion mutant was its complete absence from the cytoplasm and processes. These results showed the importance of exon-7 for cytoplasmic localization and demonstrated an abnormal accumulation of intranuclear foci from exon-7 lacking proteins. We have also performed live cell imaging of EGFP-SMN $\Delta$ Ex7 in the nucleus and noted that these foci were motile but showed no evidence of localization into the perinuclear cytoplasm, which was devoid of signal 


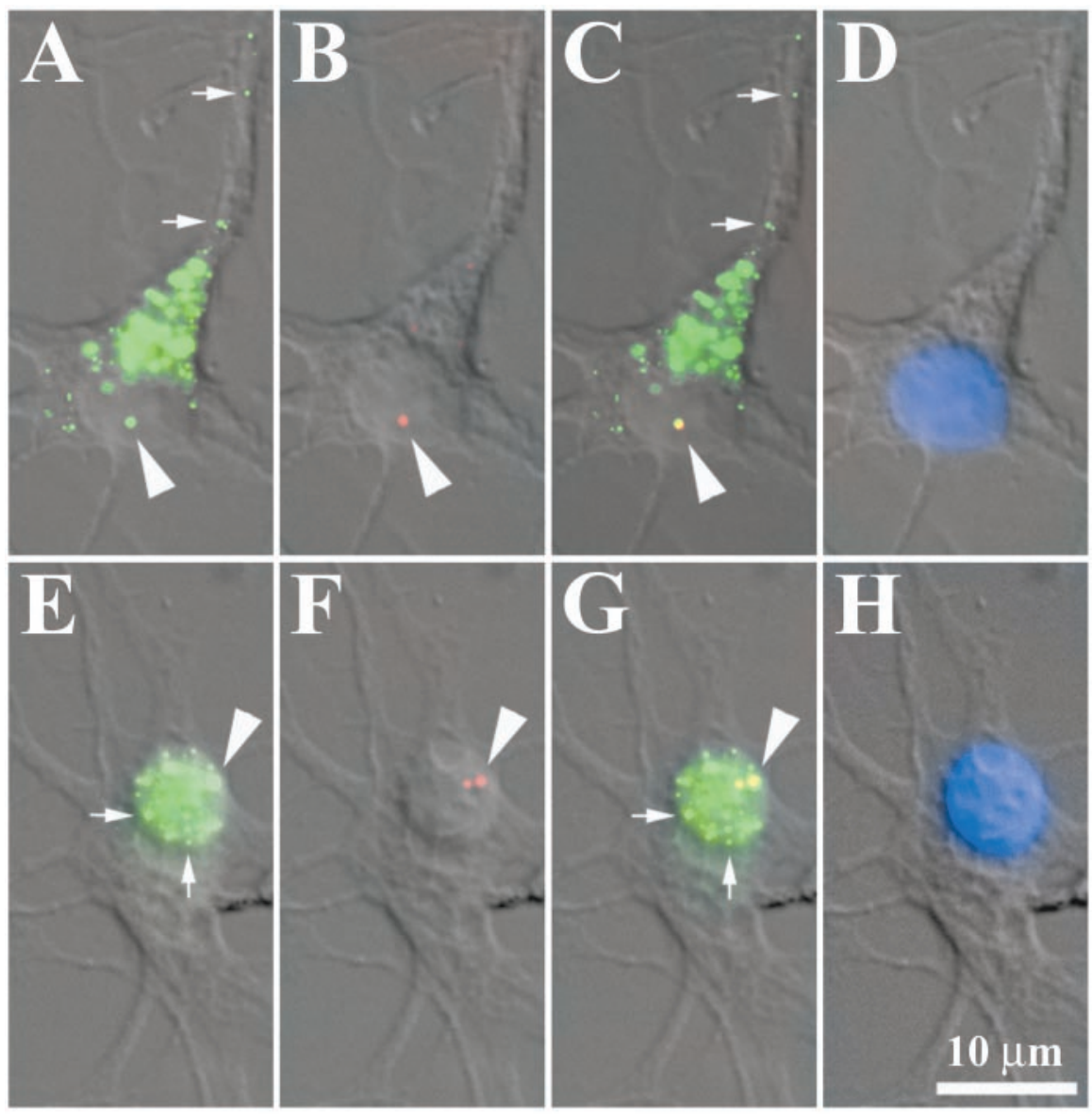

Figure 6. Nuclear aggregates in the SMN exon-7 deletion mutant were not associated with coilin. $A$, An EGFP-SMN transfected neuron showed a single nuclear foci (arrowhead). In the cytoplasm, EGFP-SMN granules were observed in processes (arrows). B, A coiled body (red) was detected with an anti-coilin antibody in the nucleus. C, EGFP-SMN foci colocalized to a coiled body in an overlay image (yellow, arrowhead). D, DAPI stained nucleus (blue). E, By contrast, an EGFP-SMN $\Delta$ Ex7 transfected neuron showed nuclear aggregation with several foci (arrows). (see also video 2, available at www.jneurosci.org). F, Coiled bodies (red) were detected in the nucleus. $G$, Overlay of images indicated two foci of EGFP-SMN $\Delta$ Ex7 association with coiled bodies. $H$, DAPI stained nucleus of the same neuron (blue).

(as supplemental data to Fig. 6E, see video 2, available at http://www.jneurosci.org).

To test whether exon-7 contained a cytoplasmic targeting signal, we fused it to a protein having an exclusive nuclear localization, and we asked whether the protein was redistributed to the cytoplasm. We selected DBF1 as a reporter, a single-stranded DNA binding protein that has been characterized as a transcription factor (Smidt et al., 1995). Transfection of EGFPDBF1 to chick forebrain neurons demonstrated a predominantly nuclear localization (Fig. 7A,B). Quantitative analysis showed that $76.6 \%$ of neurons transfected with EGFP-DBF1 showed signal only in the nucleus (Fig. $7 K$ ). The remaining $23.4 \%$ of cells also showed a perinuclear signal. However, when exon-7 was inserted into the $C$ terminus of the DBF1 in the EGFP-DBF1 construct, we detected it more frequently in the cytoplasm (Fig. 7C,D). Quantitative analysis showed that $76.8 \%$ of the transfected neurons demonstrated cytoplasmic localization of EGFP-DBF1/Ex7 (Fig. 7K). Of interest, EGFP$\mathrm{DBF} 1 / \mathrm{Ex} 7$ was not prominent in processes in a punctate pattern, as was full-length SMN, suggesting that domains other than exon-7 may be important for granule formation and transport. Nonetheless, these results did show that exon-7 could function as a cytoplasmic targeting sequence.
We designed three partially overlapping subclones of exon-7 (eight to nine amino acids each) to attempt to identify a specific amino acid sequence that was responsible for the cytoplasmic localization of SMN (Fig. 7L). Transfection of EGFP-DBF1 fused to either the proximal (Fig. $7 E, F, K$ ) or middle subregion (Fig. $7 G, H, K$ ) of exon-7 resulted in strong cytoplasmic localization of EGFP-DBF1, yet the distal subregion had only very weak cytoplasmic localization activity (Fig. 7I-K). A sequence of five amino acids, Gln-Asn-Gln-LysGlu (QNQKE), present in the overlapping proximal and middle subregions of exon-7, was shown to redistribute EGFP-DBF1 to the cytoplasm (Fig. $8 A$ ). We then asked if this QNQKE sequence could also redistribute the SMN exon-7 deletion mutant when fused in frame to EGFP-SMN $\Delta$ Ex7, which we showed earlier was confined to the nucleus (Figs. 5E, 6E). Here, we found that this five amino acid sequence was capable of restoring localization of EGFP$\mathrm{SMN} \Delta \mathrm{Ex} 7$ granules into perinuclear region and processes (Fig. $8 \mathrm{~B}$ ).

We then investigated if EGFPSMN $\Delta$ Ex7 could be redistributed by a known cytoplasmic localization sequence, in a similar manner to the putative SMN targeting sequence identified above. We used a 20 amino acid sequence from GAP-43 that is necessary for targeting to the axon (Zuber et al., 1989). The thio-ester palmitoylation at two cysteines within this targeting sequence is likely important for the attachment of GAP-43 to the cytoplasmic surface of membranous vesicles (Liang et al., 2002). Because the membrane attachment sequence was not sufficient for GAP-43 transport to growth cones (Liu et al., 1991), this suggests that other sequences are involved in kinesin-dependent transport into axons (Ferreira et al., 1992). Although SMN transport may not be normally associated with the surface of vesicles, we envisioned that the GAP-43 sequence would be an effective tool to redirect $\mathrm{SMN} \Delta \mathrm{Ex} 7$ from entering the nucleus and promote instead its cytoplasmic retention. A larger pool of SMN $\Delta \mathrm{Ex} 7$ would now be available in the soma, which in principle could be actively transported into neurites via kinesin-based transport.

The membrane-targeting sequence of GAP-43 was observed to redistribute EGFP-SMN $\Delta \mathrm{Ex} 7$ into the cytoplasm, which was now localized in granules throughout processes (Fig. $8 C$ ) and into growth cones (data not shown). Of interest, we observed in live neurons that mem/EGFP-SMN $\Delta \mathrm{Ex} 7$ granules were now actively transported in processes (see videos 3 and 4, available at www.jneurosci.org). There was also evidence for concentration of mem/EGFP-SMN $\Delta \mathrm{Ex} 7$ at submembraneous sites in growth cones and filopodia, which seemed to resemble sites of GAP-43 concentration (data not shown). The GAP-43 targeting sequence was also fused to EGFP-DBF1 (mem/EGFP-DBF1), and like the exon-7 targeting sequence, was able to redistribute EGFP-DBF1 into the cytoplasm (Fig. 8D). However, distinct granules were 
not observed in distal neurites. These data indicated that fusion of the membrane targeting sequence of GAP-43 was able to promote the cytoplasmic localization (retention) of SMN $\Delta \mathrm{Ex} 7$ and DBF1 and also granule transport of SMN $\Delta \mathrm{Ex} 7$.

\section{Reduction of neurite length by overexpression of the exon-7 deletion mutant and rescue by the GAP-43 targeting sequence}

Overexpression of SMN $\Delta \mathrm{Ex} 7$, in comparison to full-length $\mathrm{SMN}$, was characterized by shorter processes (Fig. 5), both of the minor neurites and incipient axon. To quantitate this observation, the length of the longest axon-like neurite was measured, and $>60$ transfected neurons were analyzed for each construct. A 25\% decrease in the mean axon length was shown when two exon-7 deletion mutants were compared with wild-type SMN (Fig. 9). Neurons transfected with an exon-5 deletion mutant did not show reduced axon lengths. The neurite length defect of the exon-7 deletion mutant was no longer observed when this construct was fused to the cytoplasmic targeting sequence of GAP43. This rescue of the neurite length defect was also observed with the exon-7 and exon-5 deletion mutants. These results strongly suggest that the redirection of the exon-7 deletion mutant into the cytoplasm and processes was responsible for the restoration of neurite growth.

\section{Discussion}

\section{Cytoskeletal-based transport of SMN} and other RNPs

Here we report, for the first time, that SMN was localized in granules that distribute throughout processes and growth cones in primary cultured neurons. These granules exhibited rapid, dynamic, and bidirectional movements in processes and growth cones that were characteristic of RNA granules we have previously described (Zhang et al., 2001). SMN transport at rates of $1 \mu \mathrm{m} / \mathrm{sec}$ are consistent with fast axonal transport (Hirokawa, 2000). Microtubules were involved in long distance transport of SMN granules, whereas microfilaments were involved in short-distance directed movements as well as nondirected bidirectional movements over short distances. Using a fibroblast culture system, we were able to show that SMN was associated with the Triton X-100-insoluble cytoskeleton via a primary interaction with microfilaments. These data are consistent with previous reports of RNA and mRNA binding protein interactions with predominantly microtubules in neurons and microfilaments in fibroblasts (Bassell and Singer, 2001).

Our observations of the active transport of SMN and its cytoskeletal association have important implications for under-

K
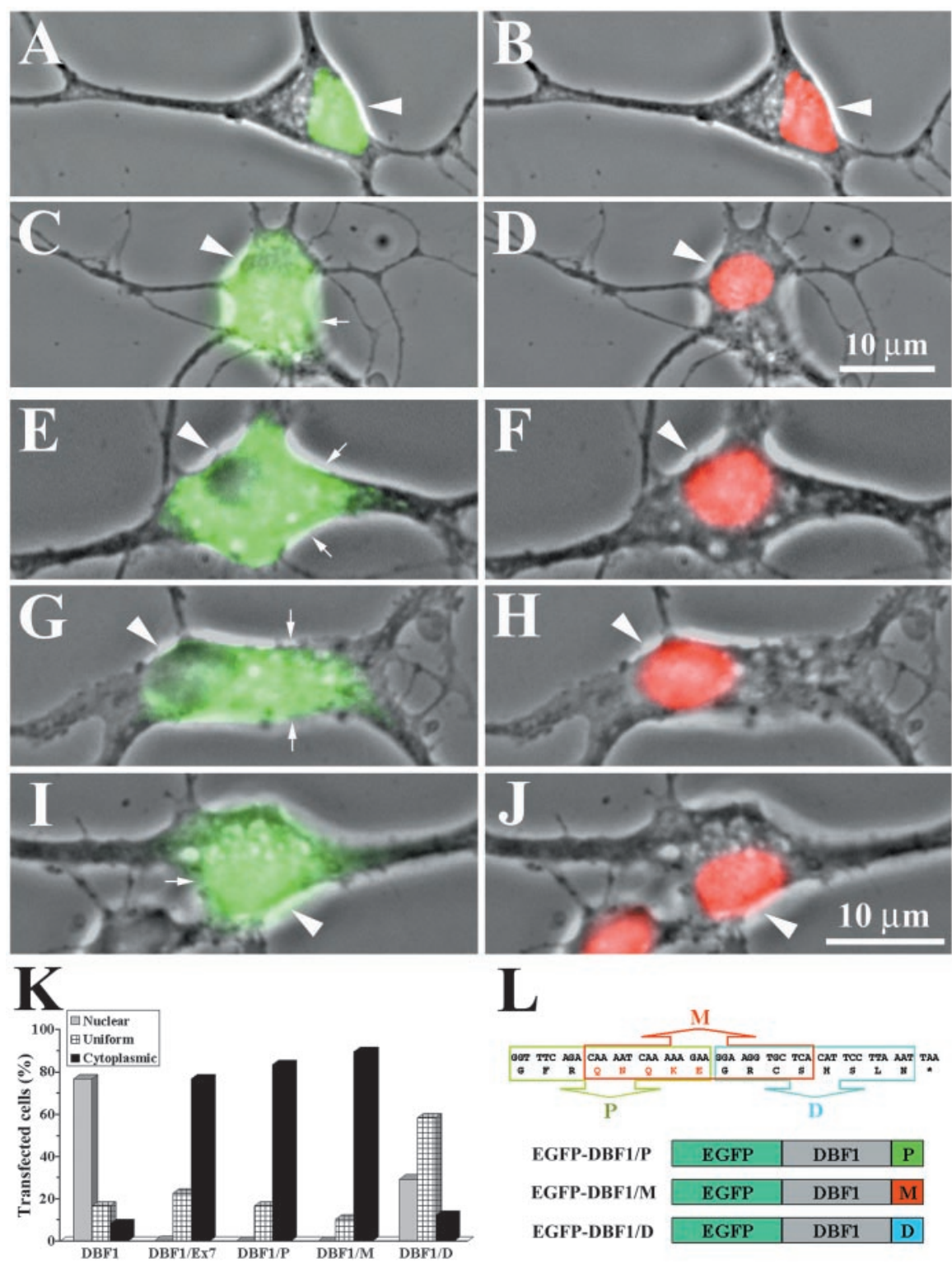

$\mathbf{L}$
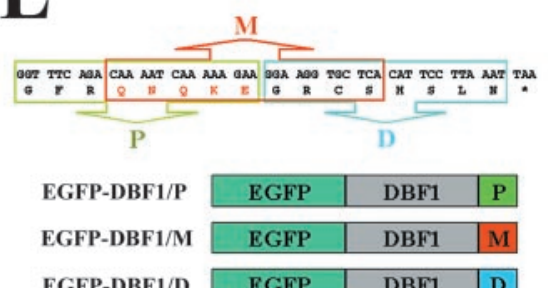

Figure 7. Fusion of SMN exon-7 to the nuclear protein, DBF1, targets it to the cytoplasm. Left panels, EGFP fusion protein signal in nucleus (arrowhead) and cytoplasm (arrows). Right panels, Location of nuclear boundary (arrowheads) using DAPI (red). A, An EGFP-DBF1 transfected neuron presented an exclusive nuclear localization of its EGFP fusion protein (arrowhead). B, DAPI stained nucleus (red). C, In contrast, an EGFP-DBF1/Ex7 transfected neuron showed fluorescence signal in the cytoplasm (arrow) beyond the (D) DAPI stained nucleus (red). E, Proximal segment of exon-7 showed clear nucleus (arrowhead) with two foci and no evidence of EGFP signal accumulation. Cytoplasmic signal (arrows) in the perinuclear region was observed beyond the (F) DAPI stained nuclear border (red). G, A similar pattern was observed when the middle segment of SMN exon-7 was fused to EGFP-DBF1. H, DAP (red). I, In contrast, the distal segment of the exon-7 was present mostly in the nucleus (arrowhead) with some signal in the perinuclear region (arrow).J, DAPI (red). K, Quantitative analysis of subcellular localization showed the percent of transfected cells with only nuclear signal, signal in both the nucleus and cytoplasm (uniform), and only cytoplasmic signal. L, Schematic of the three subregions of SMN exon-7 (P, proximal; M, middle; D, distal) that were fused to EGFP-DBF1.

standing the biological basis of SMA. A central objective in SMA research has been to understand the molecular events leading to the neurodegeneration of motor neurons. One idea is that SMN is involved in protection against neuronal cell death and apoptosis where nuclear defects, possibly attributed to altered nuclearcytoplasmic sorting of SMN, may underlie one aspect of the disease process (Vyas et al., 2002). However, immunocytochemical observations of SMN localization in neuronal processes (Battaglia et al., 1997; Bechade et al., 1999; Pagliardini et al., 2000) also suggest an axonal function for SMN, which, when perturbed, 

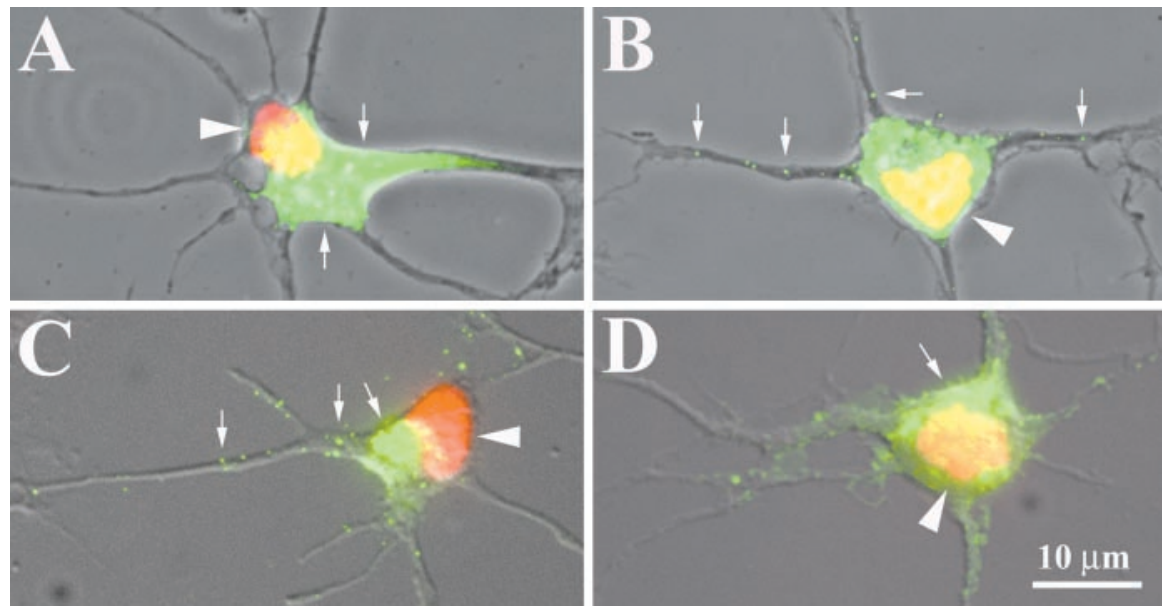

Figure 8. Redistribution of nuclear EGFP-SMN $\triangle$ Ex7 by cytoplasmic targeting sequences. A, Fusion of the QNQKE sequence to EGFP-DBF1 (EGFP-DBF1/tif) revealed signal in the cell body (arrows), but not in a granular pattern in neurites (arrow). No signal was observed within distal neurites. B, Fusion of the QNQKE sequence to EGFP-SMN $\Delta$ Ex7 (EGFP-SMN $\Delta$ Ex7/tif) resulted in the presence of granules within the cell body and processes (arrows). C, Fusion of the membrane targeting sequence of GAP-43 to EGFP-SMN $\Delta$ Ex7 (mem/EGFP-SMN $\Delta$ Ex7) resulted in its redistribution into the cytoplasm and localization of granules in neurites (arrows; see video 3 for demonstration of its active transport in axons and vide 4 for example of granule transport from the cell body into proximal neurite, both available at www.jneurosci.org). Only weak signal from the mem/EGFP-SMN $\Delta$ Ex7 was observed in the nucleus. D, The GAP-43 targeting sequence also promoted EGFP-DBF1 localization in the cytoplasm (arrow). A-D, DAPI stained nuclei (red), approximate location of nuclear border (arrowhead).

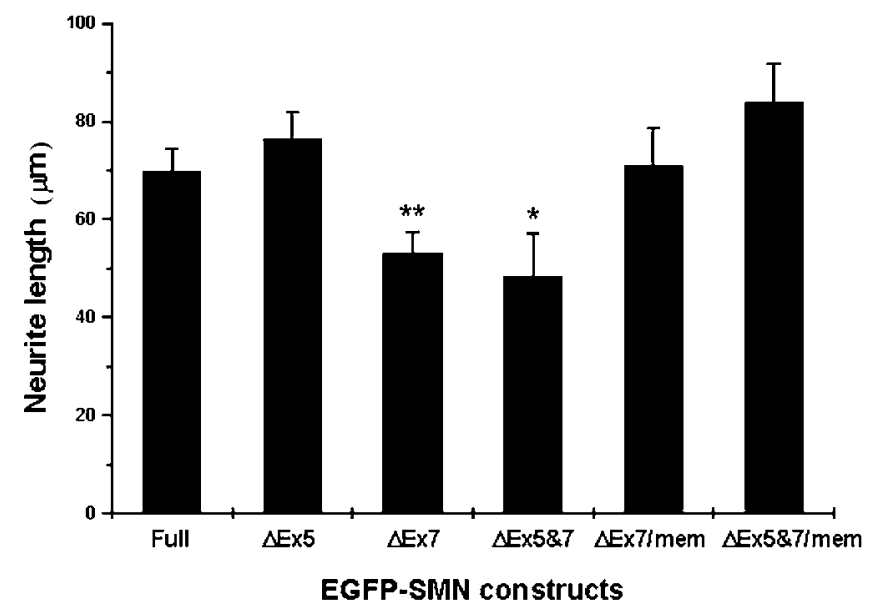

Figure 9. Decreased neurite length after overexpression of $S M N \Delta$ Ex7 was rescued by fusion of GAP-43 targeting sequence. The average length of the measured neurites is indicated in the histogram. Transfection of the SMN $\Delta$ Ex7 showed a $25 \%$ decrease in neurite length in comparison with full-length SMN. Addition of a GAP-43 membrane-targeting sequence to SMN $\Delta$ Ex7 did not show a reduction of the neurite length compared with wild-type SMN. ${ }^{* *} p<0.01$; ${ }^{*} p<0.05$ (Student's $t$ test).

could contribute to the neurodegeneration observed in SMA. Our results on the active transport of SMN granules and role of exon-7 in cytoplasmic localization make it compelling to speculate that there may be defects in the trafficking or local regulation of mRNA complexes in axons. Because exon-7 is involved in cytoplasmic localization, we suggest that SMN-associated RNPs may show inefficient delivery into axons.

There is now an emerging literature to document axonal transport defects or impairment in several mouse models of neurodegenerative diseases affecting motor neurons. Defects in tubulin transport or impaired dynein-dynactin function both result in motor neuron degeneration, with denervation of muscle also observed in the latter model (Williamson and Cleveland,
1999; LaMonte et al., 2002). In humans, motor neuron disease can involve mutation of dynactin (Puls et al., 2003). In a transgenic mouse model of progressive motor neuronopathy, a missense mutation in a tubulin-specific chaperone (Tbce) protein was shown to reduce microtubule number (Martin et al., 2002). A transgenic mouse model of SMA with a conditional knock-out of exon-7 was shown to exhibit aberrant cytoskeletal organization of motor neuron synaptic terminals and absence of terminal axon sprouting (Cifuentes-Diaz et al., 2002). We suggest that the motor neuron dysfunction and denervation may be attributable to a "dying back" axonopathy in these mice and possibly also in SMA. It will be of great interest to know if impaired axonal transport of $\mathrm{SMN}$ or its inefficient delivery can contribute to this phenotype, as is the case in other motor neuron diseases.

\section{Possible molecular mechanisms for SMN-associated RNPs in neuronal processes}

Previous studies have demonstrated direct association between SMN and mRNA binding proteins in neural cells. By yeast two hybrid and coimmunoprecipitation analysis, SMN was shown to bind FUSE binding protein (FBP) (Williams et al., 2000), a KH domain containing RNA binding protein that regulates the stability of GAP-43 mRNA (Irwin et al., 1997). A homologous protein to FBP is zipcode binding protein 2 (ZBP2), a KH domain containing protein that binds the $\beta$-actin mRNA localization sequence ( $\mathrm{Gu}$ et al., 2002). Another member of this family is MARTA1, which binds the dendritic targeting element of MAP2 mRNA and codistributes with mRNA in dendrites (Rehbein et al., 2002). It will be interesting to determine if the interaction between SMN and FBP, or its homologs, are involved in mRNA localization. In addition to FBP, yeast two hybrid and coimmunoprecipitation analysis has identified two other axonal mRNA binding proteins, hnRNP-Q and hnRNP-R, that bind to SMN (Rossoll et al., 2002). These studies further implicate some indirect association between SMN and axonal mRNP complexes.

\section{Local protein synthesis in axonal growth cones: an SMN connection?}

Our observations on the dynamic localization of SMN granules in developing axons and growth cones in primary neurons and their colocalization with rRNA, coupled with previous observations of SMN in growth cone-like protrusions in postnatal day 19 neuroblastoma cells (Fan and Simard, 2002), point to a possible connection between SMN and local protein synthesis that is necessary for the regulation of neurite outgrowth. Several recent studies point to a functional connection between mRNA localization/translation and growth cone behavior (Campbell and Holt, 2001; Zhang et al., 2001; Zheng et al., 2001; Brittis et al., 2002). The ZBP1-mediated localization of $\beta$-actin mRNA, in response to the neurotrophin, NT-3, is important for regulation of growth cone behavior (Zhang et al., 1999, 2001). Local translation of mRNA encoding the EphA2 receptor was regulated at axon pathfinding decision points and appears to involve molecular interactions mediated by cytoplasmic polyadenylation ele- 
ments (CPE) and their binding protein (CPEB) (Brittis et al., 2002).

It is possible that SMN-associated RNP complexes may similarly play a role in the regulation of growth cone behavior in response to local cues and that such mechanisms may be impaired in SMA. It is of interest to note that SMN has been detected at neuromuscular junctions in vivo, where its presence in both nerve and muscle may be essential for the proper development and spatial organization of synapses (Fan and Simard, 2002). Of interest, SMN has been shown to bind profilin II, an actinbinding protein that regulates actin polymerization (Giesemann et al., 1999). Observations of SMN in growth cones and at synapses, coupled with evidence for developmental regulation of SMN expression, suggest possible development defects in SMA.

In this study, we have established a link between the presence of SMN in the processes, the role of exon-7 and process outgrowth. The $\mathrm{SMN} \Delta \mathrm{Ex} 7$ truncated protein was shown to accumulate in the nucleus and was absent from processes. In these neurons, we noted that the neurites were $25 \%$ shorter than neurons transfected with fulllength SMN. One explanation could be a growth-promoting function of full-length SMN that is lacking in SMN $\Delta$ Ex7. Alternatively, SMN $\Delta$ Ex7 might act as a dominant negative by competing with or compromising the ability of endogenous $\mathrm{SMN} \Delta \mathrm{Ex} 7$ to interact with localized mRNPs that are important for neurite growth. Our findings that the membrane-targeting sequence of GAP-43 could redirect $\mathrm{SMN} \Delta \mathrm{Ex} 7$ into neurites and rescue the neurite length defect provide an important correlation between the presence of SMN in processes and neurite outgrowth. These data are interesting in that one of the morphologic phenotypes of the SMN $\Delta \mathrm{Ex} 7$ transgenic mice is lack of axonal sprouting (Cifuentes-Diaz et al., 2002).

\section{Cytoplasmic localization function of exon-7: implications for SMA}

Our results suggest that exon-7 contained a cytoplasmic targeting signal, QNQKE, because it behaved similarly to the cytoplasmic targeting sequence of GAP-43, in that they both could redistribute the SMN $\Delta$ Ex7 into the cytoplasm. Alternatively, QNQKE may function as a nuclear export sequence (NES), although we note no similarity to other NES sequences. Our findings of a role for exon-7 in cytoplasmic localization have important implications for understanding the disease process of SMA. Several studies have shown that SMN levels are dramatically reduced in cells from SMA patients (Coovert et al., 1997; Lefebvre et al., 1997; Burlet et al., 1998) which appears to indicate that the SMN $\Delta \mathrm{Ex} 7$ is a much less stable protein than its full-length counterpart. Also apparent in human SMA cells, from the above studies, have been observations of a lack of nuclear gems. Such observations of "no nuclear gems" in a mouse model having a conditional deletion of exon-7 have suggested a possible nuclear targeting defect (Frugier et al., 2000); however, the ascription of a direct role of exon-7 in nuclear targeting from these end-stage diseased cells is not really possible. Our results argue against a role for exon-7 in nuclear localization and indicate just the opposite because we show that the exon-7 deletion mutant is confined to the nucleus. Mutations in $S M N 1$ that cause increased expression of SMN $\Delta \mathrm{Ex} 7$ may result in an excess of nuclear SMN. Because the SMN2 gene also encodes transcripts lacking exon-7, there would be very little fulllength SMN targeted to the cytoplasm and processes in SMA, which would be compounded by the reduced stability SMN $\Delta$ Ex7.

\section{Moving away from a nucleocentric viewpoint}

The major emphasis on past SMN research has been to understand its role in snRNP and spliceosome assembly (for review, see
Terns and Terns, 2001; Paushkin et al., 2002), likely because very early reports hypothesized that Spinal Muscular Atrophy is a "splicing" disease after observation of impaired pre-mRNA splicing in extracts from patient fibroblasts (Pellizoni et al., 1998). However, 5 years later, other studies have emerged to suggest a much broader role for SMN in the assembly of diverse RNP complexes. SMN has been labeled the "master assembler" because new evidence reveals a role for SMN in regulation or processing of different classes of RNAs (Terns and Terns, 2001).

The cytoplasmic function of SMN in the nervous system may be broader in scope than analyzed thus far. We hypothesize that SMN may play a role in the assembly of $\mathrm{mRNP}$ complexes that are packaged into granules, the structures or vehicles involved in mRNA transport. We provide new evidence on the axonal transport of SMN, the molecular mechanism of SMN sorting in neurons, and a linkage between the presence of SMN in neurites and their outgrowth. These studies ultimately may provide a plausible model to explain the phenotype of SMA. The primary defect in motor neurons could be attributed to their unusually long axons, which may be dependent more critically on mRNA localization for their outgrowth and/or maintenance. The challenge ahead is clearly to identify specific mRNP complexes that may depend on SMN for their transport or local regulation in developing axons and growth cones.

\section{References}

Bassell GJ, Singer RH (2001) Neuronal mRNA localization and the cytoskeleton. In: Cell polarity and subcellular RNA localization, (Richter D, ed), pp 41-56. Berlin: Springer.

Battaglia G, Princivalle A, Forti F, Lizier C, Zeviani M (1997) Expression of the SMN gene, the spinal muscular atrophy determining gene, in the mammalian central nervous system. Hum Mol Genet 6:1961-1971.

Bechade C, Rostaing P, Cisterni C, Kalisch R, La Bella V, Pettmann B, Triller A (1999) Subcellular distribution of survival motor neuron (SMN) protein: possible involvement in nucleocytoplasmic and dendritic transport. Eur J Neurosci 11:293-304.

Brittis PA, Lu Q, Flanagan JG (2002) Axonal protein synthesis provides a mechanism for localized regulation at an intermediate target. Cell 110:223-235.

Burlet P, Huber C, Bertrandy S, Ludosky MA, Zwaenepoel I, Clermont O, Roume J, Delezoide AL, Cartaud J, Munnich A, Lefebvre S (1998) The distribution of SMN protein complex in human fetal tissues and its alteration in spinal muscular atrophy. Hum Mol Genet 7:1927-1933.

Campbell DS, Holt CE (2001) Chemotropic responses of retinal growth cones mediated by rapid local protein synthesis and degradation. Neuron 32:1013-1026.

Carvalho T, Almeida F, Calapez A, Lafarga M, Berciano MT, Carmo-Fonseca M (1999) The spinal muscular atrophy disease gene product, SMN: a link between snRNP biogenesis and the Cajal (coiled) body. J Cell Biol 147:715-728.

Cifuentes-Diaz C, Nicole S, Velasco ME, Borra-Cebrian C, Panozzo C, Frugier T, Millet G, Roblot N, Joshi V, Melki J (2002) Neurofilament accumulation at the motor endplate and lack of axonal sprouting in a spinal muscular atrophy mouse model. Hum Mol Genet 11:1439-1447.

Coovert DD, Le TT, McAndrew PE, Strasswimmer J, Crawford TO, Mendell JR, Coulson SE, Androphy EJ, Prior TW, Burghes AH (1997) The survival motor neuron protein in spinal muscular atrophy. Hum Mol Genet 6:1205-1214.

Fan L, Simard LR (2002) Survival motor neuron (SMN) protein: suggested role in neurite outgrowth and neuromuscular maturation during neuronal differentiation and development. Hum Mol Genet 11:1605-1614.

Ferreira A, Niclas J, Vale RD, Banker G, Kosik KS (1992) Suppression of kinesin expression in cultured hippocampal neurons using antisense oligonucleotides. J Cell Biol 117:595-606.

Frugier T, Tiziano FD, Cifuentes-Diaz C, Miniou P, Roblot N, Dierich A, Le Meur M, Melki J (2000) Nuclear targeting defect of SMN lacking the C-terminus in a mouse model of spinal muscular atrophy. Hum Mol Genet 9:849-858.

Frugier T, Nicole S, Cifuentes-Diaz C, Melki J (2002) The molecular bases of spinal muscular atrophy. Curr Opin Genet Dev 12:294-298. 
Germain-Desprez D, Brun T, Rochette C, Semionov A, Rouget R, Simard LR (2001) The SMN genes are subject to transcriptional regulation during cellular differentiation. Gene 279:109-117.

Giesemann T, Rathke-Hartlieb S, Rothkegel M, Bartsch JW, Buchmeier S, Jockusch BM, Jockusch H (1999) A role for polyproline motifs in the spinal muscular atrophy protein SMN. Profilins bind to and colocalize with smn in nuclear gems. J Biol Chem 274:37908-37914.

Gu W, Pan F, Zhang HL, Bassell GJ, Singer RH (2002) A predominantly nuclear protein affecting cytoplasmic localization of b-actin mRNA in fibroblasts and neurons. J Cell Biol 156:41-51.

Hirokawa N (2000) Kinesin and dynein superfamily proteins and the mechanism of organelle transport. Science 279:519-526.

Irwin N, Baekelandt V, Goritchenko L, Benowitz LI (1997) Identification of two proteins that bind to a pyrimidine-rich sequence in the $3^{\prime}$ untranslated region of GAP-43 mRNA. Nucleic Acids Res 25:1281-1288.

La Bella V, Cisterni C, Salaun D, Pettmann B (1998) Survival motor neuron $(\mathrm{SMN})$ protein in rat is expressed as different molecular forms and is developmentally regulated. Eur J Neurosci 10:2913-2923.

LaMonte BH, Wallace KE, Holloway BA, Spencer SS, Ascano J, Tokito M, VanWinkle T, Howland DS, Holzbaur EL (2002) Disruption of dynein/ dynactin inhibits axonal transport in motor neurons causing late onset progressive degeneration. Neuron 34:715-727.

Lefebvre S, Burglen L, Reboullet S, Munnich A, Melki J (1995) Identification and characterization of a spinal muscular atrophy determining gene. Cell 80:155-165.

Lefebvre S, Burlet P, Liu Q, Bertrandy S, Clermont O, Munnich A, Dreyfuss G, Melki J (1997) Correlation between severity and SMN protein level in spinal muscular atrophy. Nat Genet 16:265-269.

Liang X, Lu Y, Neubert TA, Resh MD (2002) Mass spectrometric analysis of GAP-43/neuromodulin reveals the presence of a variety of fatty acylated species. J Biol Chem 277:33032-33040.

Liu Q, Dreyfuss G (1996) A novel nuclear structure containing the survival of motor neurons protein. EMBO J 15:3555-3565.

Liu YC, Chapman ER, Storm DR (1991) Targeting of neuromodulin (GAP43) fusion proteins to growth cones in cultured rat embryonic neurons. Neuron 6:411-420.

Martin N, Jaubert J, Gounon P, Salido E, Haase G, Szatanik M, Guenet JL (2002) A missense mutation in Tbce causes progressive motor neuron neuronopathy in mice. Nat Genet 32:443-447.

Pagliardini S, Giavazzi A, Setola V, Lizier C, Di Luca M, DeBiasi S, Battaglia G (2000) Subcellular localization and axonal transport of the survival motor neuron $(\mathrm{SMN})$ protein in the developing rat spinal cord. Hum Mol Genet 9:47-56.

Paushkin S, Gubitz AK, Massenet S, Dreyfuss G (2002) The SMN complex, an assemblyosome of ribonucleoproteins. Curr Opin Cell Biol 14:305-312.

Pellizoni L, Kataoka N, Charroux B, Dreyfuss G (1998) A novel function for
SMN, the spinal muscular atrophy disease gene product, in pre-mRNA splicing. Cell 95:615-624.

Puls I, Jonnakuty C, LaMonte BH, Holzbaur EL, Tokitoa M, Floeter MK, Bidus K, Drayna D, Oh SJ, Brown RH, Ludlow CL, Fischbeck KH (2003) Mutant dynactin in motor neuron disease. Nat Genet 33:455-456.

Rehbein M, Wege K, Buck F, Schweizer M, Richter D, Kindler S (2002) Molecular characterization of MARTA1, a protein interacting with the dendritic targeting element of MAP2 mRNAs. J Neurochem 82:1039-1046.

Rossoll W, Kroning AK, Ohndorf UM, Steegborn C, Jablonka S, Sendtner M (2002) Specific interaction of Smn, the spinal muscular atrophy determining gene product, with hnRNP-R and gry-rbp/hnRNP-Q: a role for Smn in RNA processing in motor axons? Hum Mol Genet 11:93-105.

Smidt MP, Russchen B, Snippe L, Wijnholds J, Ab G (1995) Cloning and characterisation of a nuclear, site specific ssDNA binding protein. Nucleic Acids Res 23:2389-2395.

Terns MP, Terns RM (2001) Macromolecular complexes: SMN-the master assembler. Curr Biol 11:R862-R864.

Vyas S, Bechade C, Riveau B, Downward J, Triller A (2002) Involvement of survival motor neuron (SMN) protein in cell death. Hum Mol Genet 11:2751-2764.

Williams BY, Hamilton SL, Sarkar HK (2000) The survival motor neuron protein interacts with the transactivator FUSE binding protein from human fetal brain. FEBS Lett 470:207-210.

Williamson TL, Cleveland DW (1999) Slowing of axonal transport is a very early event in the toxicity of ALS-linked SOD mutants to motor neurons. Nat Neurosci 2:50-56.

Wirth B (2000) An update of the mutation spectrum of the survival motor neuron gene (SMN1) in autosomal recessive spinal muscular atrophy (SMA). Hum Mutat 15:228-237.

Young PJ, Le TT, Nguyen TM, Burghes AH, Morris GE (2000) The relationship between SMN, the spinal muscular atrophy protein, and nuclear coiled bodies in differentiated tissues and cultured cells. Exp Cell Res 256:365-374.

Zhang HL, Eom T, Oleynikov Y, Shenoy SM, Lieblet DA, Dictenberg JB, Singer RH, Bassell GJ (2001) Neurotrophin induced transport of betaactin mRNP complex increases beta-actin levels and stimulates growth cone motility. Neuron 31:261-275.

Zhang HL, Singer RH, Bassell GJ (1999) Neurotrophin regulation of betaactin mRNA and protein localization within growth cones. J Cell Biol 147:59-70.

Zheng JQ, Kelly TK, Chang B, Rytzantsev S, Rajasekaran AK, Martin KC, Twiss JL (2001) A functional role for intra-axonal protein synthesis during axonal regeneration from adult sensory neurons. J Neurosci 21:9291-9303.

Zuber MX, Strittmatter SM, Fishman MC (1989) A membrane-targeting signal in the amino terminus of the neuronal protein GAP-43. Nature 341:345-348. 